\title{
Who will Help in Situations of Intimate Partner Violence: Exploring Personal Attitudes and Bystander Behaviours
}

\author{
Kathryn Lazarus and Tania Signal ${ }^{*}$
}

\author{
Central Queensland University, School of Human, Health and Social Sciences, Rockhampton, Qld, 4701, \\ Australia
}

\begin{abstract}
Intimate partner violence (IPV) continues to be a problem within society, with many studies focusing on general attitudes toward violence against women as a gauge of positive societal change in this area. To investigate whether individual personal attitudes toward violence against women were predictive of prosocial bystander behaviours in situations of IPV, 157 Australian community members completed an online survey. This survey investigated the factors of bystander intention, bystander self-efficacy, general and privacy attitudes toward violence against women, fear of intervening and the effects/impact of psychological abuse as predictors of willingness to intervene in IPV situations. Bystander intention, self-efficacy and gender were significantly associated with willingness to intervene, whilst respondent's attitudes toward violence against women was not. The implications of these findings for promoting social control and bystander intervention in situations of IPV are discussed.
\end{abstract}

Keywords: Intimate partner violence, domestic violence, bystander behaviour, attitudes toward violence against women, informal social control.

Intimate partner violence (IPV) is a pervasive social problem in Australia as it is worldwide. IPV can be defined as the threat or actual use of physical, sexual or emotional force by spouses or anyone with a close relationship with their intended victim (Gibbons, 2011). While it is important to acknowledge that men can be the target of IPV, women are more vulnerable to family violence than to violence in any other context (OWP, 2002), and are more likely to be the targets of this form of violence than men (ABS, 2005). Statistics show that in Australian communities, violence against women and children is at epidemic proportions. For example, in a survey conducted by the Australian Bureau of Statistics, it was found that since age fifteen, 160,000 Australian women had experienced current partner violence, and 1,135,500 had experienced violence from a previous partner (ABS, 2005).

\section{THE IMPACT OF SOCIAL NORMS}

It was not until the introduction of the Domestic and Family Violence Protection Act in 1989 that IPV was acknowledged as a crime in Australia, providing women with a legal avenue to protect themselves from further abuse. Even so, research shows that approximately $63 \%$ of IPV incidents go unreported to the police (Cismaru, Jensen, \& Lavack, 2010). Reasons for under-reporting are complex but may be due, in part, to the pervasive public perception that IPV is a private matter that is often viewed as being less

*Address correspondence to this author at the School of Human, Health and Social Sciences - Psychology, Central Queensland University, Building 32, Rockhampton, Qld, 4701, Australia; Tel: +61 74923 2147; Fax: + 6174930 6460; E-mail: t.signal@cqu.edu.au important than violence between strangers (VicHealth, 2004). Additionally, female victims reliance on the perpetrator's salary for housing and basic necessities (Davies, Ford-Gilboe, \& Hammerton, 2009) as well as fears of retaliation, loneliness and an inability to 'make it on their own' (Dziegielewski, Campbell, \& Turnage, 2005) can make it extremely difficult for women to remove themselves from situations of IPV.

This is a reflection of community attitudes toward IPV, with social norms playing a very important role in shaping the broader social environment that result in either condoning or punishing violence against women (VicHealth, 2006). Attitudes indicative of gendered social norms in situations of family violence often find individuals asking the question, "Why doesn't she just leave"? This cultural attitude rests within the misconception that men and women are treated equally in relationships, remaining ignorant of the fact that IPV is rooted within the broader social context of our everyday lives and embedded within socially structured arrangements of power and control (Davies et al., 2009).

Social norms are the unspoken but prevalent rules and assumptions that determine how people should and should not behave and respond in certain situations (Aiken \& Goldwasser, 2010). According to Social Norms Theory, people are generally very concerned with how others view them, which provides great motivation to conduct oneself in ways that the individual believes will gain approval and avoid disapproval (Aiken \& Goldwasser; VicHealth, 2011). According to Berkowitz (2004), social norms can result 
in an overestimation of the perceptions of problem behaviours, such as tolerant peer attitudes toward family violence, and an underestimation of healthy or protective behaviours, such as bystander intervention in abusive situations (McMahon \& Dick, 2011). As such, these inaccurate perceptions may serve to decrease a bystander's willingness to intervene in situations of IPV. For example, Carlson (2008) found that a large barrier for men intervening in IPV situations was their concern that their peers would see them as "weak or gay [sic]" (p. 16). As a result, due to the perceived social norms of others, men or other family members who do not condone IPV may actually be inhibited from speaking up or taking action as bystanders.

\section{BYSTANDER BEHAVIOURS AND PERSONAL ATTITUDES TOWARD IPV}

Importantly, a bystander's attitudes and beliefs (social norms) play an important role in how they respond to an incident of IPV (VicHealth, 2006). What is more, recent evidence reveals that many people are aware of, or suspect they know of, someone who is a victim of IPV (Beeble, Post, Bybee \& Sullivan, 2008). Beeble et al.'s (2008) study is significant as it highlights the fact that there are potentially a large number of individuals who could intervene to help those being abused and accentuates the important need for community involvement or informal social control (ISC) in response to IPV.

Drawn from Social Disorganisation Theory, ISC can be conceptualised as neighbourhood cohesion in the form of informal community surveillance (daily casual observation of the neighbourhood) and/or direct intervention (residents confronting other people in regards to questionable behaviours, Warner, Beck, \& Ohmer, 2010). This form of ISC is suggested to be effective in establishing social norms within neighbourhoods as well as sending a message that the community is one that is cohesive and safe (Warner et al., 2010). For example, a study by Gracia and Herrero (2007) found that participants who perceived low to moderate social disorder in their neighbourhood had more positive attitudes toward reporting violence against women, compared to those with perceptions of high neighbourhood social disorder. These findings suggest that higher levels of perceived social disorder within a neighbourhood result in a lack of willingness on the part of residents (i.e., bystanders), to engage in informal social control (i.e., to intervene). From a feminist perspective, however, it is questionable as to whether IPV would be deemed a sign of social disorder within a neighbourhood setting, when violence against women has not historically been considered deviant behaviour (Frye, 2007).

Today, IPV is generally considered inappropriate behaviour, with the majority viewing it as a crime (VicHealth, 2010). Despite this, IPV is often not reported and silence continues to be the prevalent community response (Gracia \& Herrero, 2007). This reaction to IPV is of concern, as public attitudes which are passive and indifferent toward IPV effectively condone such behaviours, reducing both accountability and consequences for perpetrators, and making it much more difficult for women to speak up and feel they will be protected and supported if they choose to leave the violent relationship (Gracia \& Herrero, 2007). In addition, women's social conditioning to remain silent about what is happening to them within the privacy of their home (Aiken \& Goldwasser, 2010), is perpetuated through social silence to IPV. The prevailing issue of IPV being seen as a private matter was revealed in a study by Frye (2007) where it was found that attitudes that reflected IPV being a private issue, were significantly associated with ISC of IPV. Furthermore, unlike Gracia and Herrero (2007) who found that social disorder and reporting were positively associated with reporting IPV, Frye reported that social cohesion and visible disorder within the community was not a significant predictor of ISC. The discrepancy between these two findings may be indicative of Gracia and Herrero's study measuring attitudes toward reporting IPV and Frye's study measuring behavioural intention in the form of ISC. Importantly, this inconsistency may also reflect differences between stated attitudes and actual behaviours as predictors of ISC in IPV situations, and as such, is an important issue that warrants further investigation (Frye et al., 2012).

Social psychologists have attempted for many years to understand the influence that people's attitudes have on subsequent and corresponding behaviours (Ajzen \& Fishbein, 1977), with the attitude-behaviour relation often found to reveal large variability between ones reported attitudes and actual behaviours. A metaanalysis by Glasman and Albarracín (2006) found that memory recall played an important part in the relation between attitudes and behaviour, specifically that only when attitudes are easy to recall and stable over time do they predict behaviour. The continual expressing of particular attitudes, having concern about a certain issue and also having direct experience with the 
attitude object were all found to predict behaviour. Interestingly, this study also found that the more thought that an individual gave to a particular issue, the more accessible the associated attitude would be, which in turn promoted behaviour-relevant information (Glasman \& Albarracín, 2006). This is an important point when considering attitude-behaviour relations in the context of IPV, which has been a relatively neglected area of research. It could be theorised that due to IPV consistently being ignored by society, emerging intolerant community attitudes toward IPV may not result in appropriate behavioural responses. For example, Gracia and Herrero (2006) reported in their study examining community attitudes and behaviours toward female victims of partner violence, that public discussion of the issue was significantly correlated with attitudes that were positive in regards to reporting. However the researchers also reported that failure to intervene remained the most common reaction of those who were aware of incidents of IPV.

The phenomenon of the "diffusion of responsibility" is one of the most explored bystander theories (Darley \& Latané, 1968), which led to the creation of the fivestep situational model of the intervention process. This five stage model describes this process as first noticing an event, perceiving it as an emergency (ambiguity of the situation), taking personal responsibility, deciding the appropriate action to take, and feeling that one has that appropriate knowledge and skills to safely take action (Latané \& Darley, 1970). Utilising the five-step model, understanding of bystander behaviour in emergency situations has grown over the last five decades. To date, much of the bystander literature has focused on bystander intervention in situations of sexual violence (e.g., Banyard \& Moynihan, 2011), with much less being known about prosocial bystander behaviour in the specific context of IPV (Frye et al., 2012). In a recent study, Banyard and Moynihan (2011) examined attitudinal and bystander behavioural variables associated with college students who reported intervening to help others at risk of relationship or sexual violence. They reported that bystanders were more likely to help when they possessed a better awareness of the problem, were involved in a peer group less likely to use coercion in relationships, supported fewer rape myths and had higher bystander self-efficacy. Somewhat contradictory findings were also found with those who held attitudes more supportive of coercion in relationships, and/or with higher rape myth acceptance also reported a higher likelihood of helping behaviours in situations of sexual violence.
Results such as these along with the dearth of research into bystander behaviours in situations of IPV highlight the need to look more closely at both community attitudes and bystander behaviours in a variety of IPV situations. As such rather than looking specifically at attitudes toward violence against women, bystander behavioural intention in the context of IPV may be a more important factor in understanding the complexity of social norms and how likely an individual may be to intervene. A recent study by Frye et al., (2012) examining ISC and willingness to intervene in an IPV related situation highlighted the need for research that examines the relation that safety concerns and desire to maintain privacy have on bystander intentions.

Gender (of the bystander) appears to be a significant predictor of willingness to intervene or engage in ISC in situations of IPV. Beeble et al., (2008) reported that women were $18 \%$ more likely than men to help in IPV situations irrespective of other demographic characteristics like age or SES. Similarly, Signal and Taylor (2008) reported that, within a large community cohort of Australians, women were significantly more likely to report IPV than men, however overall propensity to report was influenced by an awareness of whom to report to and age of participant. West and Wandrei (2002) presented college-age participants with fictional (video) scenarios of IPV and found that women were more likely to engage in helpful behaviours.

As such three hypotheses were addressed in the current project. Firstly that individuals who express greater willingness to intervene will also indicate higher levels of bystander intention and self-efficacy, a greater knowledge of psychological abuse (as part of IPV), less fear of intervening and attitudes that are not reflective of IPV being a private issue. Secondly, it is hypothesised that attitudes towards violence against women will not be a significant predictor of willingness to intervene. Lastly, from previous research regarding intervening in interpersonal and IPV situations, there is a priori expectation that women within this study will be more likely to intervene than men.

\section{METHOD}

\section{Participants}

The participants consisted of 157 Australian adult community members, including 37 males and 120 females. The mean age was 38.78 years $(S D=12.97)$ with the majority having completed a University level 
education and having relatively high incomes (over AUS $\$ 80,000)$. Participants voluntarily completed an online questionnaire in response to notices placed on Facebook, within CQUniversity education forums, text messages and emails.

\section{Procedure}

Participants were provided with a link to a website comprising the survey, containing a total of 51 questions (copies of the survey instrument are available from the second author). An initial information sheet was provided containing details of the study, such as the overview of the project, the benefits and risks along with how confidentiality and anonymity would be maintained. Ethics was applied for, and granted, via Central Queensland University Human Research Ethics Committee. The survey was titled "Personal attitudes and bystander behaviours" to avoid biasing selection.

\section{Measures}

In order to maximise return rate, survey items were kept to a minimum. To ensure content validity for each measure, a careful empirical literature review on attitudes towards violence against women and bystander behaviours was conducted. As existing scales were found to focus more on sexual violence, it was decided that items from a range of measures would be included when they related specifically to IPV and/or more generalised violence. All items were answered on a 5-point Likert scale, with higher scores indicating greater endorsement of each scale topic.

\section{Informal Social Control}

This scale assessed respondent's level of agreement with how willing they would be to intervene in various scenarios involving active intimate partner violence. It included all three items from Frye's (2007) measure, with each item ranging from an ambiguous level of violence (e.g. "A couple is fighting in the street and it appears that the man is about to hit the woman") to highly specific violence (e.g. "a man is hitting his wife in the street"). Scores were created by summing responses across items. Internal consistency for this scale was $\alpha=.72$.

\section{General Attitudes Toward Violence Against Women}

This scale measured attitudes toward IPV (e.g. "I find it hard to understand why women stay in violent relationships") and was constructed using 4 items from the NCAS survey (VicHealth, 2010), 2 items out of 45 from the Attitudes and Beliefs about Helping Victims of Intimate Partner Violence scale (Beeble et al., 2008) and 3 items out of 4 from the Attitudes toward Intimate Partner Violence against Women scale (Frye, 2007). An aggregate across all 9 items was created, with an obtained internal consistency score of $\alpha=.57$.

\section{Knowledge of Psychological Abuse}

This scale was constructed using 4 items from the NCAS survey (VicHealth, 2010). Questions were used to measure respondent's level of knowledge of psychological abuse as a form of IPV (e.g. "A man controlling the social life of his partner by preventing contact with friends/family"). Scores were achieved by summing all items and internal consistency reached a score of $\alpha=.87$.

\section{Privacy Attitudes Toward Violence Against Women}

This measure was created using 4 out of 5 items from Frye's (2007) Privacy Attitude scale. Items were used to reflect the belief that IPV against women is a private issue (e.g. "Neighbours should mind their own business about their neighbour's marriages/ relationships"). Additionally, one item was used from the NCAS survey ("Most people turn a blind eye to, or ignore domestic violence") (VicHealth, 2010). The internal consistency score obtained for this scale was $\alpha$ $=.52$.

\section{Fear of Intervening}

This 6-item scale used questions from Banyard, Plante, and Moynihan's (2005) 10-item Decisional Balance scale, reflecting the negative consequences only of intervening in a violent situation where someone could get hurt (e.g. "I could get physically hurt by intervening"). Additionally, one item was written by the author based on McMahon and Dick's (2011) research, which found that many men do not intervene in IPV situations as they are afraid they will make the situation worse ("Intervening could make the situation worse; it's safer for everyone if I just walk away"). Scores were created by summing responses across the items, and the obtained internal consistency was $\alpha=.81$.

\section{Bystander Self-Efficacy}

This 10 -item scale used 7 out of 10 items from the Mentors in Violence Program Efficacy scale (as cited in Banyard, Plante, \& Moynihan, 2005) and 3 out of 4 items from Frye's (2007) Self-Efficacy to Intervene in IPV scale. This scale assessed bystander's level of self-efficacy when dealing with issues involving IPV (e.g. "I know of a place in my community where women 
can go for help with domestic violence"). Scores were created by aggregating the items and internal consistency reached $\alpha=.80$.

\section{Bystander Intention}

This scale used 9 items from Banyard, Plante and Moynihan's (2005) 51 item Bystander Behaviours scale and assessed behavioural inclination to act in a manner which openly challenges IPV against women in a wide variety of environments and contexts. Some items were reworded to reflect an IPV scenario within an Australian context, with two items reworded to include a situation of IPV in a public context to assess diffusion of responsibility (e.g. "If a woman is being shoved or yelled at by a man in a public place, I would approach her and ask her if she needs help"). Scores were created by summing responses across items and the obtained internal consistency score for this scale was $\alpha=.82$

\section{Sociodemographic Factors}

As age, gender, education level and household income have all been shown to be predictors of helping behaviour in previous studies, these variables were also assessed.

\section{RESULTS}

Prior to undertaking the main analyses, each variable of interest was examined through the SPSS 19.0 program for accuracy of data entry, missing values, applicable assumptions, and outliers. A principal component factor analysis indicated that items used did fall within the general scales proposed; copies of this are available from the corresponding author.

Table 1 presents the descriptive statistics for each sociodemographic predictor variable. Most respondents were willing to intervene in situations of IPV to some degree, with the mean for ISC $(M=3.46)$ being

Table 1: Descriptive Statistics for Nominal and Continuous Predictor Variables

\begin{tabular}{|c|c|c|c|c|c|c|c|c|}
\hline \multicolumn{9}{|c|}{ Nominal variables } \\
\hline \multicolumn{3}{|c|}{ Variable } & \multicolumn{3}{|c|}{$n$} & \multicolumn{3}{|c|}{$\%$} \\
\hline \multicolumn{9}{|l|}{ Gender } \\
\hline \multicolumn{3}{|c|}{ Male } & \multicolumn{3}{|c|}{37} & \multicolumn{3}{|c|}{23.6} \\
\hline \multicolumn{3}{|c|}{ Female } & \multicolumn{3}{|c|}{120} & \multicolumn{3}{|c|}{76.4} \\
\hline \multicolumn{9}{|l|}{ Education Level } \\
\hline \multicolumn{3}{|c|}{ University degree } & \multicolumn{3}{|c|}{81} & \multicolumn{3}{|c|}{51.6} \\
\hline \multicolumn{3}{|c|}{ Tafe/Trade Certificate/Diploma } & \multicolumn{3}{|c|}{40} & \multicolumn{3}{|c|}{25.5} \\
\hline \multicolumn{3}{|c|}{ Year 12} & \multicolumn{3}{|c|}{21} & \multicolumn{3}{|c|}{13.4} \\
\hline \multicolumn{3}{|c|}{ Year 10} & \multicolumn{3}{|c|}{10} & \multicolumn{3}{|c|}{6.4} \\
\hline \multicolumn{3}{|c|}{ Did not finish school } & \multicolumn{3}{|c|}{5} & \multicolumn{3}{|c|}{3.2} \\
\hline \multicolumn{9}{|l|}{ Household Income } \\
\hline \multicolumn{3}{|c|}{$<\$ 39,000$} & \multicolumn{3}{|c|}{26} & \multicolumn{3}{|c|}{16.6} \\
\hline \multicolumn{3}{|c|}{$\$ 40,000-\$ 79,000$} & & & & & 29. & \\
\hline & & & & & & & 51.6 & \\
\hline & & dinal & ntinuo & riables & & & & \\
\hline Variable & Min & Max & $M$ & $S D$ & & & & \\
\hline & & & & & Stat. & $\begin{array}{l}\text { Std. } \\
\text { Error }\end{array}$ & Stat. & $\begin{array}{l}\text { Std. } \\
\text { Error }\end{array}$ \\
\hline Age & 19 & 80 & 38.78 & 12.97 & .64 & .22 & -.04 & .43 \\
\hline Informal Social Control & 3 & 15 & 3.46 & .83 & -.50 & .19 & .26 & .39 \\
\hline General Attitudes & 27 & 45 & 4.11 & .40 & -.18 & .19 & -.15 & .39 \\
\hline Psychological Abuse & 8 & 20 & 4.12 & .52 & .03 & .19 & .81 & .39 \\
\hline Privacy Attitudes & 6 & 16 & 2.20 & .41 & .29 & .19 & .18 & .39 \\
\hline Fear & 6 & 29 & 2.23 & .75 & .86 & .19 & .77 & .39 \\
\hline Bystander Self-efficacy & 21 & 49 & 3.67 & .57 & -.19 & .19 & -.28 & .39 \\
\hline Bystander Intention & 20 & 45 & 3.73 & .58 & -.20 & .20 & -.29 & .39 \\
\hline
\end{tabular}

Note. $N=157$. Stat: Statistic. Std: Standard. 
somewhat higher than that reported by Frye (2007) ( $M$ $=2.51)$ and this difference proved to be significant $t$ $(156)=14.34, p<.001, r=.75$.

A stepwise multiple regression analysis was used to test the hypotheses that individuals who express greater willingness to intervene will also endorse greater bystander intentions, greater bystander selfefficacy, greater knowledge of psychological abuse, less fear of intervention and attitudes that are not reflective of IPV being a private issue. In addition, it was hypothesised that general individual attitudes towards violence against women would not be a significant predictor of willingness to intervene, and that women would be more likely to intervene compared to men.

Bystander intention was the first predictor entered into the model and this variable explained the majority of the variance in the outcome of ISC. Bystander selfefficacy was found to account for the next greatest amount of variance, followed lastly by gender. There were no interactions found between gender and bystander intention or self-efficacy. The results shown in Table 2, indicate that the model was significant, $F(3$, $119)=46.21, p<.001$, and accounted for $53.8 \%$ of the variance of ISC scores. Partial correlations revealed that, after controlling for other predictors, bystander intention accounted for $27 \%$ of total individual willingness to intervene, and bystander self-efficacy explained $9 \%$ of the variance. Cross-validation of the model via the adjusted $R^{2}$ statistic revealed that if the model were derived from the general population, it would account for approximately $1 \%$ less variance in the outcome than the model derived from this sample.

As hypothesised, women were found to be more likely to intervene than men, with partial correlations revealing that gender accounted for $4 \%$ of the outcome variance after controlling for other predictors. A followup split file by gender multiple regression revealed that bystander self-efficacy was a significant predictor of male's willingness to intervene, $F(1,22)=23.84, p<$ .001 , and bystander intention was significantly and positively associated with female's performance of ISC, $F(1,96)=108.33, p<.001$. Furthermore, univariate tests revealed that women's scores $(M=37.47, S E=$ .31) for general attitudes toward violence against women were significantly higher than men $(M=35.46$, $S E=.68), t(155)=-2.97, p<.01, r=.23$, along with women's acknowledgement of psychological abuse as a form of IPV $(M=17.00, S E=.24)$ also being greater than men's $(M=16.05, S E=.42), t(155)=-1.96, p=$ $.05, r=.15$.

Further exploratory examination of individual items in the bystander intention scale revealed some interesting findings (Bonferroni adjustments were made to the critical values to compensate for the multiple analyses). Firstly, a chi-square comparison of the two questions, "I would call 000 if I heard someone yelling and fighting" and "I would call 000 if I heard someone call for help" revealed that a total of $90.2 \%$ of participants would be likely or highly likely to call the police if they heard a call for help, compared to $42.5 \%$ who heard yelling and fighting (see Figure 1). These findings reveal that participants are significantly less likely to call the police when they hear yelling and fighting compared to when they hear a call for help $\left(x^{2}=\right.$ 23.07, $p<.001)$. Please note however, that some cells had expected counts less than 5 .

An additional chi-square comparison of the two questions "If I saw a friend grabbing, pushing or insulting their partner, I would confront them" and "If I saw a stranger grabbing, pushing or insulting their

Table 2: Stepwise Multiple Regression Analysis Predicting Informal Social Control in Intimate Partner Violence Situations

\begin{tabular}{|c|c|c|c|c|c|}
\hline Variables & B & SE B & $\beta$ & $t$ & Partial \\
\hline Bystander Intention & .25 & .03 & .53 & $6.63^{* * *}$ & .52 \\
\hline Bystander Self-efficacy & .12 & .04 & .27 & $3.38^{* * *}$ & .30 \\
\hline Gender & -.85 & .37 & -.15 & $-2.34^{*}$ & -.21 \\
\hline$R 2$ & .54 & & & & \\
\hline Adjusted $R 2$ & .53 & & & & \\
\hline F statistic & 46.21 & & & & \\
\hline$p$-value for $F$ statistic & .000 & & & & \\
\hline
\end{tabular}

${ }^{*} p<.05 .{ }^{* *} p<.01 .{ }^{* * *} p<.001$ 

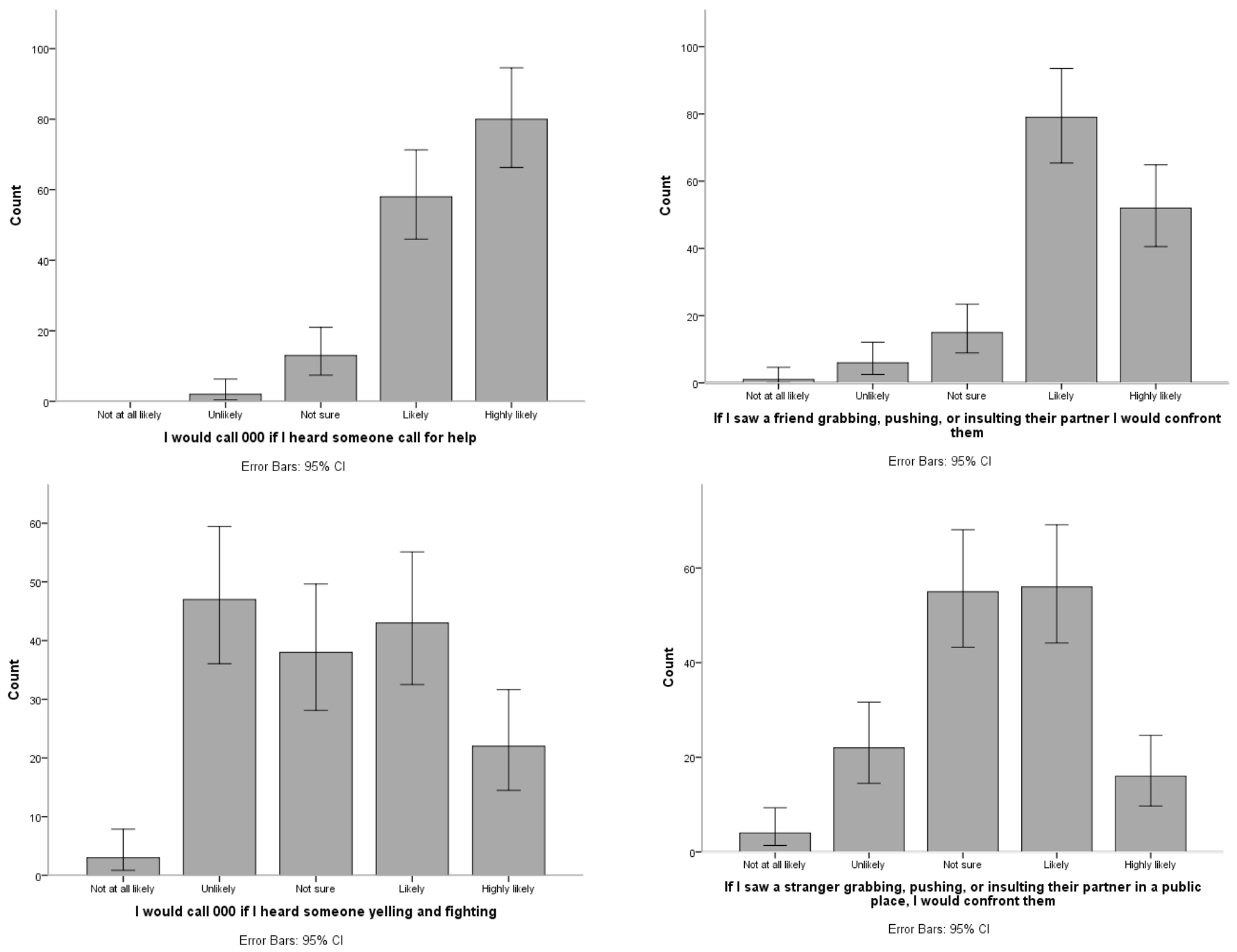

Figure 1: Comparison of willingness to intervene upon hearing yelling and fighting and hearing a call for help.

partner in a public place, I would confront them", showed that $85.6 \%$ of respondents would be likely or highly likely to confront a friend, compared to $47.1 \%$ who would confront a stranger (see Figure 2). As such, participants are significantly less likely to confront a stranger who was being abusive toward their partner, compared to a friend $\left(x^{2}=44.82, p<.001\right)$. Please note that some cells had less than 5 expected counts.

Finally, a comparison between the questions "If I heard what sounds like yelling or fighting in my neighbour's house, I would call the police" and "If I heard what sounds like yelling or fighting in my neighbour's house, I would go over and knock on the door to see if everything is okay", found that $49 \%$ of participants were likely or highly likely to call the police, compared to just $24.2 \%$ who would confront their neighbour (see Figure 3). Respondents were significantly less likely to confront their neighbours

Figure 2: Comparison of willingness to intervene between a perpetrator who is a friend and a stranger.

directly if they heard potential abuse next door, compared to calling the police $\left(x^{2}=13.70, p<.01\right)$.

\section{DISCUSSION}

This study explored the relationship between personal attitudes toward violence against women and bystander behaviours relating to predicted willingness to intervene in situations of IPV. The hypothesis that those who endorsed greater bystander intentions and bystander self-efficacy would also show greater willingness to intervene, was supported. Results also supported the hypothesis that general attitudes toward violence against women would not be predictive of an individual's willingness to intervene in situations of IPV. However, the variables of knowledge of psychological abuse (as part of IPV), fear of intervention and attitudes reflective of "IPV being a private matter", were found to have no significant association with the outcome of ISC of violence against women. 


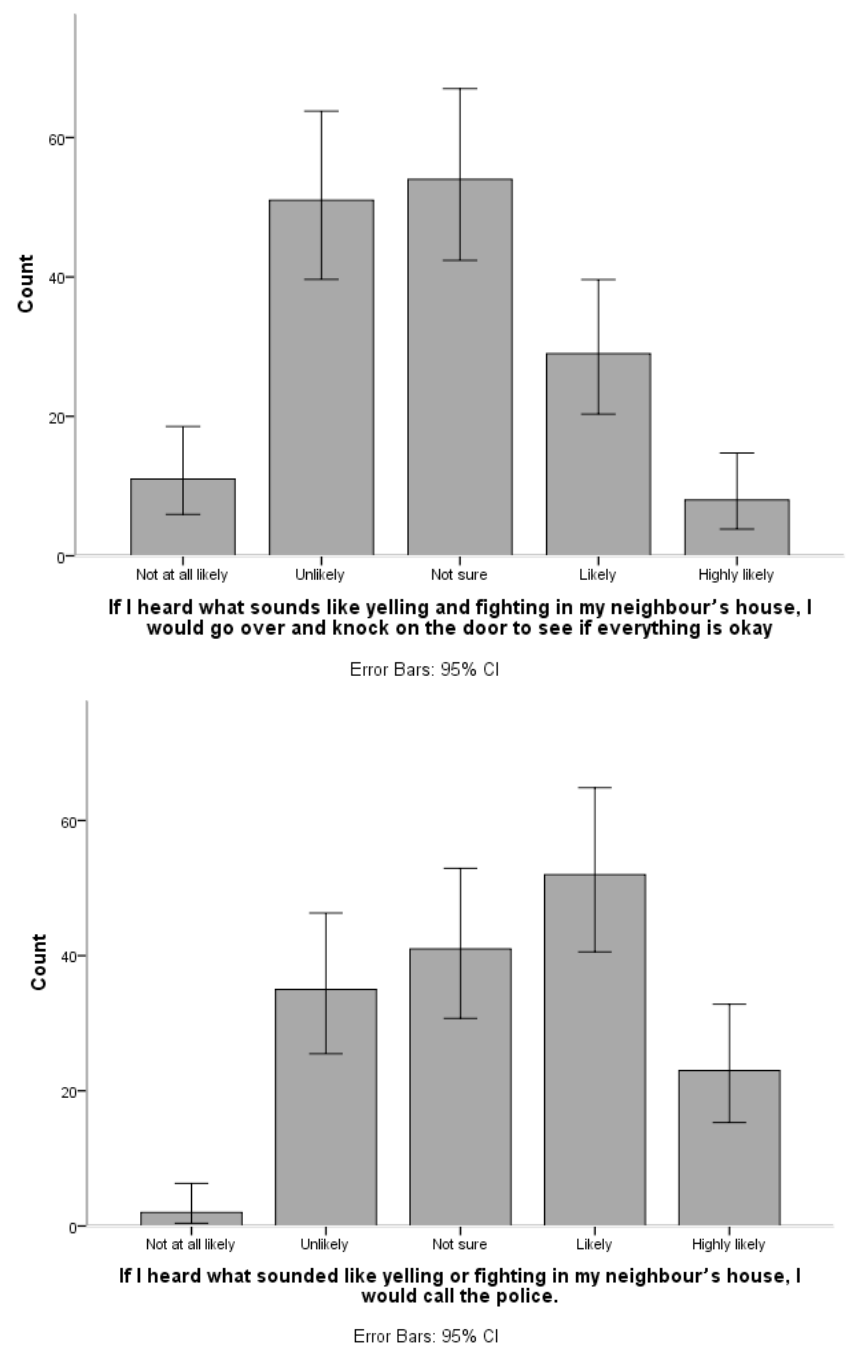

Figure 3: Comparison of willingness to intervene between confronting neighbours directly and calling the police.

The finding that bystander intention was a significant predictor of ISC of IPV, but that personal attitude toward violence against women was not, is arguably the most important finding of the current study. This result concurs with Gracia and Herrero's (2006) finding that participant's attitudes were inconsistent with their behaviour when it came to intervening in situations of IPV. Such evaluative inconsistency between one's attitude and behaviour is in keeping with social psychological research, which has often found large variability between verbalised attitudes and corresponding behaviours. Glasman and Albarracín's (2006) findings (that continual expression of a particular attitude along with having concern about the issue, makes it more likely that the individual will act on that attitude), when considered alongside the discrepancy found between stated attitudes and behaviours within this study, highlights the importance of discussing the problem of IPV within our society in a much more open and frank manner. With community attitudes toward violence against women showing improvements over time, within this study (e.g., respondents hold highly intolerant attitudes toward IPV) and more broadly (VicHealth, 2006), it would be expected that a bystanders willingness to intervene within family violence situations would mirror this attitude; however, the results from this study clearly show that this is not the case. Thus, when considering the attitude-behaviour discrepancy found within this study in conjunction with Glasman and Albarracín's findings, it suggests that perhaps due to IPV continuing to be treated as a private matter (i.e., social norms) and rarely spoken about, the corresponding behavioural response that should follow these more intolerant attitudes may be being suppressed. For example, the attitude of "not getting involved" was evident in the statement from a neighbour of a woman whose husband has recently been charged with her murder in Australia (Davies \& Calligeros, 2012). Even though the neighbour heard screams that were loud and concerning enough to go outside with a torch and investigate, he stated that "Obviously, now I think I should have phoned the police, but you don't think about these things when it happens" (Murray, 2012, para. 20). As such, an important consideration in regards to future efforts in education and media campaigns concerning IPV, should specifically highlight the importance of treating IPV as a social rather than private issue, and emphasise the enduring consequences for not only the children and partners involved, but society at large.

Bystander self-efficacy, or confidence as a bystander, was also found to be a significant predictor of willingness to intervene in IPV situations, and this result is consistent with a number of previous studies investigating bystander behaviours generally (e.g., Banyard \& Moynihan, 2011). This finding is also in agreement with the fourth step of Latané and Darley's five-step situational model of the intervention process (Latané \& Darley, 1970) in that a bystanders level of confidence is a critical factor when deciding what action to take. The finding of "confidence in skills" to intervene as a chief aspect of engagement in bystander behaviour in situations of sexual and intimate partner violence, signifies the importance of educating the community as to how individuals can safely intervene in situations of family violence, and is a crucial factor that should be included in the development of future intervention programs for bystanders.

Similar to previous studies (e.g., Banyard \& Moynihan, 2011), gender was found to be a significant 
predictor of ISC of IPV against women, with women stating a higher willingness to intervene than men. More specifically, a follow-up analysis revealed that bystander self-efficacy was a significant predictor of men's willingness to intervene, while bystander intention was significantly associated with women's intention to intervene. This is an interesting finding and has important implications for future prevention programs aimed at teaching skills to potential bystanders. Frye et al., (2012) reported that intervention behaviours that were perceived as being of low risk (to the bystander), required minimal effort and/or invoked formal systems (e.g., calling the Police) were rated as more likely to occur and as more effective by their participants. Taken together these results suggest that men and women are more likely to intervene if they feel they have the aptitude and confidence to do so, and that their efforts are going to be effective. As such, future education and media campaigns should be targeted at informing individuals how to safely intervene in situations of IPV as bystanders. By encouraging bystanders to intervene, this may in turn increase the social costs and consequences for perpetrators (and therefore ISC), which may also facilitate a reduction in the occurrences of family violence.

Unexpectedly, knowledge of psychological abuse, specific fear of the consequences of intervention (e.g., individuals may be concerned they will make the situation worse by intervening) and attitudes which are not reflective of "IPV being a private matter", revealed no association with ISC of IPV against women. The finding that fear was not a predictor of intervening may be due to the social desirability bias of self-report questionnaires. An interesting possibility for future research would be to incorporate questions that ask participants to rate their neighbours likelihood of intervening, Frye et al., (2012) suggests that neighbour ratings may be a more realistic (i.e., less optimistic) rating of bystander intention. Certainly, the highly dissimilar circumstances between filling out an online form and making a split-second decision due to fear related factors when witnessing an IPV incident may yield very different conclusions from respondents. As such, a potentially important factor that was not measured within this study was whether (or not) participants had first-hand experience in witnessing and/or intervening in, an IPV situation. When it comes to fear, this information may have yielded valuable comparisons between those who had witnessed an IPV incident, and those who had not. As this is one of the first studies to explore fear as a factor in responding to IPV situations, future research is needed to further explore how the fear of the bystander impacts on decision-making. The finding that privacy attitudes toward IPV failed to statistically predict bystander intervention was in direct contrast to Frye's (2007) findings and particularly unexpected given the common perception of IPV being a private issue (Aiken \& Goldwasser, 2010). This result may have been due to a number of reasons, including the poor internal consistency of the privacy attitudes measure $(\alpha=.52)$ and/or social desirability bias, and as such, warrants further investigation.

As highlighted in the results while the vast majority of participants would be likely or highly likely to call the police if they heard a call for help, less than half would call if they heard yelling and fighting. It is unclear from the current study why people are much less likely to call when hearing yelling, screaming or fighting, compared to a call for help. One possibility may be due to the prevailing social norm of family violence being a private matter and individual's inaccurate perceptions that others would also not get involved (Aiken \& Goldwasser, 2010). It appears from this data, that unless a victim of violence is actually calling for help, bystander's are generally unwilling to get involved in the situation. This may be an important factor to consider in future research, as there are currently no studies (to the author's knowledge) that have explored how a victim of IPV responds verbally to the violence and how this relates to bystander responses. Another possible explanation for this finding may be the ambiguity of the situation, which is in agreement with the second step of Latané and Darley's (1970) five-step model. Bystanders may feel intimidated at the thought of calling the police if there is not significant evidence of a potentially life threatening situation in progress. In order to decrease this perceived barrier to calling the police, what may be needed are education campaigns which encourage people to call the police, even if they are unsure there is an emergency in progress. Possibly, promoting the use of the telephone number of local police stations, or emphasising the low (personal) risk of making such a call may reduce the intimidation that is present when calling emergency services.

The finding that less than half the participants were likely to notify police if they heard yelling or fighting from a neighbour's house suggests that the majority of people are not willing to become involved when an IPV situation involves a neighbour. The reason for this lack of willingness to become involved could be due to a 
number of factors, such as fear of retaliation from the neighbour, or a sense of diffusion of responsibility in that other neighbours overhearing the situation may deal with the situation instead. This finding is in agreement with the evidence that although many people are aware of IPV situations (Nabi, MeehanStarck, \& Sunderland, 2000) the violence usually goes unreported to the police (Gracia \& Herrero, 2007).

In agreement with the NCAS survey (VicHealth, 2010), findings revealed that the majority of individual's display attitudes which are unaccepting of IPV. For example, most of the respondents endorsed "Men who hit their wives should be arrested for it". However, victim-blaming attitudes were still apparent (e.g., over half the participants agreed with the statement "Most women could leave a violent relationship if they really wanted to").

Several limitations of this study need to be noted. Firstly, like most studies which utilise self-report measures of bystander intentions, this study is susceptible to social desirability biases (Burn, 2008). The mean score for fear of intervening was quite low and while this may be an accurate score for this particular sample of respondents, it may also have resulted from participants choosing the response which they imagined they would ideally engage in if a violent IPV situation arose in their presence. As such, respondents may have been reluctant to acknowledge that their decision may have been largely influenced by thoughts of negative evaluations by others, along with concerns of feeling humiliated if they made a wrong decision. Similarly, participant's intention to intervene was measured through self-report, rather than via actual observation of intervention. Thus, it can only be assumed that the reported intervention behaviours would be undertaken in actual situations. However, as already mentioned, how one behaves when confronted with a real-life IPV situation may be very different to how one "imagines" they may react while filling out a questionnaire. Lastly, due to the poor internal consistency of both the general attitude and privacy attitude measures, the results gleaned from these scales need to be interpreted with caution. It should also be noted that the method of recruitment (i.e., online snowball sampling) resulted in self-selected participation and a large disparity in female:male participant numbers - these characteristics may limit the generalizability of the findings on one hand but also point to an area in need of further research (i.e., men's willingness to engage in ISC).
In conclusion, this investigation was an exploratory examination of community attitudes toward IPV against women and related bystander behaviours when witness to violence against women. This study revealed that individuals who showed greater willingness to intervene in IPV situations also endorsed greater bystander intentions and bystander selfefficacy. In addition, women were found to be more likely to intervene in IPV situations than men, whilst men's level of self-efficacy and women's level of intention were found to be significantly associated with ISC. Importantly, results also revealed that general individual attitudes toward violence against women were not predictive of intervention behaviours in situations of IPV. This study therefore provides empirical support for the theory that there can be large variability between an individual's stated attitude and the overt behaviour that one engages in. When considered in conjunction with previous meta-analytic evidence, it can be further theorised that the very limited public acknowledgement and discussion in regards to the impact of IPV, encourages pluralistic ignorance and lessens individual's feelings of personal responsibility to intervene. In addition, the finding that self-efficacy is an important predictor of bystander behaviour highlights the importance of educating the community as to how to intervene safely in situations of IPV. This research has revealed the importance of speaking-up about, and educating the population in regards to IPV. Such education should include highlighting the consequences of socially structured relations of gender inequality within our society, as well as emphasising the social stigma and silence that currently surrounds women in abusive relationships, and how this stigma impacts a bystander's decision to intervene.

\section{REFERENCES}

ABS. 2005. "Personal Safety Survey." Canberra: Australian Bureau of Statistics. Retrieved from http://www.abs.gov.au/

Aiken, Jane H. and Katherine Goldwasser. 2010. "The Perils of Empowerment." Cornell Journal of Law and Public Policy 20:139-180

Ajzen, Icek and Martin Fishbein. 1977. "Attitude-behavior Relations: A Theoretical Analysis and Review of Empirical Research." Psychological Bulletin 84(5):888-918. http://dx.doi.org/10.1037/0033-2909.84.5.888

Banyard, Victoria L. and Mary M. Moynihan. 2011. "Variation in Bystander Behavior Related to Sexual and Intimate Partner Violence Prevention: Correlates in a Sample of College Students." Psychology of Violence 1(4):287-301. http://dx.doi.org/10.1037/a0023544

Banyard, Victoria L., Elizabeth G. Plante and Mary M. Moynihan. 2005. "Rape Prevention Through Bystander Education: Bringing a Broader Community Perspective to Sexual Violence Prevention." U.S. Department of Justice. 
Beeble, Marisa L., Lori A. Post, Deborah Bybee and Cris M. Sullivan. 2008. "Factors Related to Willingness to Help Survivors of Intimate Partner Violence." Journal of Interpersonal Violence 23(12):1713-1729.

http://dx.doi.org/10.1177/0886260508314333

Berkowitz, Alan D. 2004. "The Social Norms Approach: Theory, Research and Annotated Bibliography." http://www.alanberkowitz.com/articles/social_norms.pdf

Burn, Shawn M. 2008. "A Situational Model of Sexual Assault Prevention Through Bystander Intervention." Sex Roles 60(11-12):779-792.

http://dx.doi.org/10.1007/s11199-008-9581-5

Carlson, Melanie. 2008. "I'd Rather Go Along and Be Considered A Man: Masculinity and Bystander Intervention." The Journal of Men's Studies 16(1):3-17. http://dx.doi.org/10.3149/ims.1601.3

Cismaru, Magdalena, Gitte Jensen and Anne M. Lavack. 2010. "If The Noise Coming From Next Door Were Loud Music, You'd Do Something About It." Journal of Advertising 39(4):69-82. http://dx.doi.org/10.2753/JOA0091-3367390405

Darley, John M. and Bibb Latané. 1968. "Bystander Intervention in Emergencies: Diffusion of Responsibility. Journal of Personality and Social Psychology 8:377-383. http://dx.doi.org/10.1037/h0025589

Davies, Lisa and Marissa Calligeros. 2012. "Allison Baden-Clay's Husband Charged With Murder." The Sydney Morning Herald, April 29.

Davies, Lorraine, Marilyn Ford-Gilboe and Joanne Hammerton. 2009. "Gender Inequality and Patterns of Abuse Post Leaving." Journal of Family Violence 24(1):27-39. http://dx.doi.org/10.1007/s10896-008-9204-5

Dziegielewski, Sophia F., Katharine Campbell and Barbara F. Turnage. 2005. "Domestic Violence: Focus Groups from the Survivors' Perspective. Journal of Human Behavior in the Social Environment 11(2):9-23 http://dx.doi.org/10.1300/J137v11n02 02

Frye, Victoria. 2007. "The Informal Social Control of Intimate Partner Violence Against Women: Exploring Personal Attitudes and Perceived Neighborhood Social Cohesion." Journal of Community Psychology 35(8):1001-1018. http://dx.doi.org/10.1002/jcop.20209

Frye, Victoria, Margaret M. Paul, Mary-Justice Todd, Veronica Lewis, Malik Cupid, Jane Coleman, Cristina Salmon and Patricia O'Campo. 2012. "Informal Social Control of Intimate Partner Violence Against Women: Results From a Concept Mapping Study of Urban Neighbourhoods." Journal of Community Psychology 40(7):828-844. http://dx.doi.org/10.1002/jcop.21493

Gibbons, Lynda. 2011. "Dealing with the Effects of Domestic Violence." Emergency Nurse 19(4):12-17.

Glasman, Laura R. and Dolores Albarracín. 2006. "Forming Attitudes That Predict Future Behavior: A Meta-Analysis of the Attitude-Behavior Relation." Psychological Bulletin 132(5):778-822. http://dx.doi.org/10.1037/0033-2909.132.5.778

Gracia, Enrique and Juan Herrero. 2006. "Public Attitudes Toward Reporting Partner Violence Against Women and Reporting Behavior. Journal of Marriage and Family, 68:759-768. http://dx.doi.org/10.1111/i.1741-3737.2006.00288.x
Gracia, Enrique and Juan Herrero. 2007. "Perceived Neighborhood Social Disorder and Attitudes Toward Reporting Domestic Violence Against Women." Journal of Interpersonal Violence 22(6):737-752.

http://dx.doi.org/10.1177/0886260507300755

Latané, Bibb and John M. Darley. 1970. "Characteristics of Emergencies and the Intervention Process." Pp. 29-36 in The Unresponsive Bystander: Why Doesn't He Help? New York: Appleton-Century-Crofts.

McMahon, Sarah and Alexandria Dick. 2011. "Being in a Room with Like-Minded Men': An Exploratory Study of Men's Participation in a Bystander Intervention Program to Prevent Intimate Partner Violence." The Journal of Men's Studies 19(1):3-18. http://dx.doi.org/10.3149/jms.1901.3

Murray, David. 2012. "Allison Baden-Clay's neighbours startled by screams in the night, suddenly muffled." Courier Mail, June 14.

Nabi, Robin, Tracy Meehan-Starck and Antonia Sunderland. 2000 "Attitudes and beliefs about domestic violence: The results of a survey of adults in Philadelphia." Philadelphia: The Annenberg Public Policy Centre.

OWP. 2002. "A Policy Framework: A Co-Ordinated Approach to Reducing Violence Against Women." Women's Safety Strategy, Office of Women's Policy: Victorian Government, Australia.

Signal, Tania and Nicola Taylor. 2008. "Propensity to Report Intimate Partner Violence in Australia: Community Demographics." Behavior \& Social Issues 17:8-19. http://dx.doi.org/10.5210/bsi.v17i1.1759

VicHealth. 2004. "The Health Costs of Violence: Measuring the Burden of Disease Caused by Intimate Partner Violence. A Summary of Findings." Melbourne: Victorian Heath Promotion Foundation, Australia.

VicHealth. 2006. "Two Steps Forward, One Step Back. Community Attitudes to Violence Against Women. Progress and Challenges in Creating Safe and Healthy Environments for Victorian Women." Melbourne: Victorian Heath Promotion Foundation, Australia.

VicHealth. 2010. "National Survey on Community Attitudes to Violence Against Women 2009. Changing Cultures, Changing Attitudes - Preventing Violence Against Women. A Summary of Findings." Melbourne: Victorian Heath Promotion Foundation, Australia.

VicHealth. 2011. "Review of Bystander Approaches in Support of Preventing Violence Against Women." Mebourne: Victorian Health Promotion Foundation, Australia.

Warner, Barbara D., Elizabeth Beck and Mary L. Ohmer. 2010. "Linking Informal Social Control and Restorative Justice: Moving Social Disorganization Theory Beyond Community Policing." Contemporary Justice Review 13(4):355-369. http://dx.doi.org/10.1080/10282580.2010.517960

West, Angelique and Mary L.Wandrei. 2002. "Intimate Partner Violence: A Model for Predicting Interventions by Informal Helpers. Journal of Interpersonal Violence 17:972-986. http://dx.doi.org/10.1177/0886260502017009004

(C) 2013 Lazarus and Signal; Licensee Lifescience Global.

This is an open access article licensed under the terms of the Creative Commons Attribution Non-Commercial License (http://creativecommons.org/licenses/by-nc/3.0/) which permits unrestricted, non-commercial use, distribution and reproduction in any medium, provided the work is properly cited. 